\title{
Percutaneous Transhepatic Cholangioscopy in Bilioenteric Anastomosis Stricture
}

\author{
Hyoung-Chul Oh \\ Division of Gastroenterology, Department of Internal Medicine, Chung-Ang University College of Medicine, Seoul, Korea
}

Bilioenteric anastomosis strictures are a serious complication of biliary surgery, and often result in recurrent cholangitis, choledocholithiasis, biliary cirrhosis, and hepatic failure. Bilioenteric reconstructive surgery is the standard treatment of choice for such complications. However, percutaneous transhepatic cholangioscopy (PTCS), also known as per-oral endoscopic-guided intervention, is a less invasive procedure that is becoming an increasingly popular alternative. This review describes the PTCS procedure (including the preparation process), as well as the diagnostic and therapeutic role of PTCS in bilioenteric anastomosis strictures. Clin Endosc 2016;49:530-532

Key Words: Cholangioscopy; Constriction, pathologic; Anastomosis

\section{INTRODUCTION}

Bilioenteric anastomosis strictures may be caused by benign conditions such as postoperative fibrotic change and scarring, or malignant conditions such as tumor recurrence. ${ }^{1-3}$ They are a serious complication of biliary surgery, and may result in recurrent cholangitis, choledocholithiasis, biliary cirrhosis, and hepatic failure. Bilioenteric reconstructive surgery is performed for patients with bilioenteric anastomosis stricture complications. However, this surgery is difficult to perform, and its success rate decreases with each successive surgery. ${ }^{2,47}$ The percutaneous transhepatic cholagioscopy (PTCS) or peroral endoscopy-guided intervention is less invasive procedure that has become an increasingly popular alternative for managing bilioenteric anastomostic strictures. With the increase in the number of liver transplantations-especially living-donor transplantations-over the last few decades, the therapeutic

Received: August 24, 2016 Revised: August 31, 2016

Accepted: September 1, 2016

Correspondence: Hyoung-Chul Oh

Division of Gastroenterology, Department of Internal Medicine, Chung-Ang University Hospital, Chung-Ang University College of Medicine, 102 Heukseok-ro, Dongjak-gu, Seoul 06973, Korea

Tel: +82-2-6356-3637, Fax: +82-2-6299-1383, E-mail: ohcgi@cau.ac.kr

(cc) This is an Open Access article distributed under the terms of the Creative Commons Attribution Non-Commercial License (http://creativecommons.org/ licenses/by-nc/3.0) which permits unrestricted non-commercial use, distribution, and reproduction in any medium, provided the original work is properly cited. role of PTCS has become even more important.

\section{PROCEDURES}

PTCS-guided interventions are laborious procedures, which require multi-step preparation before cholangioscopic intervention can be performed. First, percutaneous transhepatic biliary drainage (PTBD) is performed with an 8.5-Fr catheter inserted under fluoroscopic guidance into the right posterior branch or left peripheral branch of the intrahepatic duct, based on a planned anatomical approach to the stricture. Two or 3 days after PTBD, the percutaneous tract is dilated to allow for the passage of the cholangioscope. This is usually done by one-stage dilation (e.g., from 8.5 to 16 or 18 Fr) or stepwise dilation in two sessions. For sinus tract maturation, a 16- or 18-Fr PTC catheter is placed at least 7 days before cholangioscopy. Cholangioscopy is then performed using a $5-\mathrm{mm}$ diameter cholangioscope. ${ }^{8,9}$

Procedure-related complications tend to occur during PTBD insertion (12.9\%), tract dilation (12.8\%), and tract maturation (6.9\%). Cholangitis and bacteremia are the most frequent complications. The incidence of complications for therapeutic cholangioscopies has been reported to be $6.7 \%$, of which cholangitis and bile duct injuries are the commonest complications. ${ }^{9}$ 


\section{CHOLANGIOSCOPY}

\section{Diagnostic role}

It is essential to be able to diagnose a bilioenteric anastomosis stricture accurately, because the choice of treatment depends on whether the cause is benign or malignant. Tissue acquisition is the mainstay of diagnosis. However, in bilioenteric anastomosis strictures, access is limited by the surgically altered anatomy and the limited visualization of the stricture site via a retrograde approach. As such, it is almost impossible to obtain a tissue sample with endoscopic retrograde cholangiopancreatography or single (or double) balloon enteroscopy. Instead, PTCS can play an important diagnostic role by allowing the direct visual inspection of a bilioenteric anastomotic lesion in an antegrade approach. ${ }^{10}$

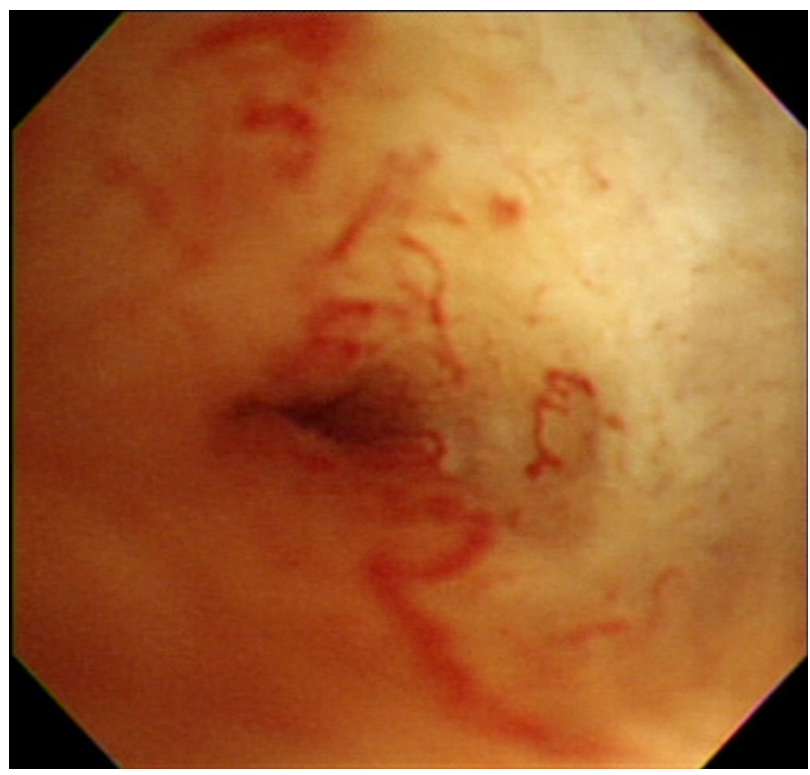

Fig. 1. Cholangioscopy image shows malignant tumor vessels at the biliary stricture site.
The typical cholangioscopic findings of a benign biliary stricture include the following: smooth mucosal surface, tapered luminal narrowing, short stricture segment (accompanying stones), and the absence of definite neovascularization (tumor vessel). ${ }^{11}$ A tumor vessel is an abnormally proliferating and tortuous vascular structure on the bile duct mucosa, and is one of the defining characteristics of biliary malignancy (Fig. 1). ${ }^{12}$ PTCS-guided target biopsies allow the direct visualization of tumor vessels. They were found to improve diagnostic accuracy significantly, especially in infiltrative cholangiocarcinoma. They had a sensitivity of $96 \%$, specificity of $100 \%$, positive predictive value of $100 \%$, and negative predictive value of $91 \%{ }^{12}$

\section{Therapeutic role}

PTCS has several advantages over percutaneous cholangiography-guided interventions in treating bilioenteric anastomosis strictures. Due to the presence of bile stasis and remnant suture materials, postoperative bilioenteric anastomosis strictures are often complicated by bile duct stones. Large stones proximal to the stricture site can be easily fragmented with electrohydraulic shock-wave lithotripsy or laser lithotripsy, and then removed during stricture dilation. In addition, since remnant suture materials or surgical clips can act as niduses for stone formation, it is essential to remove any foreign bodies present at the bilioenteric anastomosis stricture site. ${ }^{13,14}$

The main role of PTCS in bilioenteric anastomosis strictures is the recanalization and dilation of the strictures. Due to postoperative fibrosis and scarring, the strictures are often pinpoints (Fig. 2). PTCS guides the targeted recanalization with a guidewire or needle-knife. ${ }^{15,16}$ The initial technical success rate was reported as $100 \%$; however, the recurrence rate was $38 \%$ at a mean of 17 months. The overall success rate after repeated dilation was $82 \%$ after a mean follow-up period of 33 months, and the 5 -year cumulative patency rate was $48 \%$.
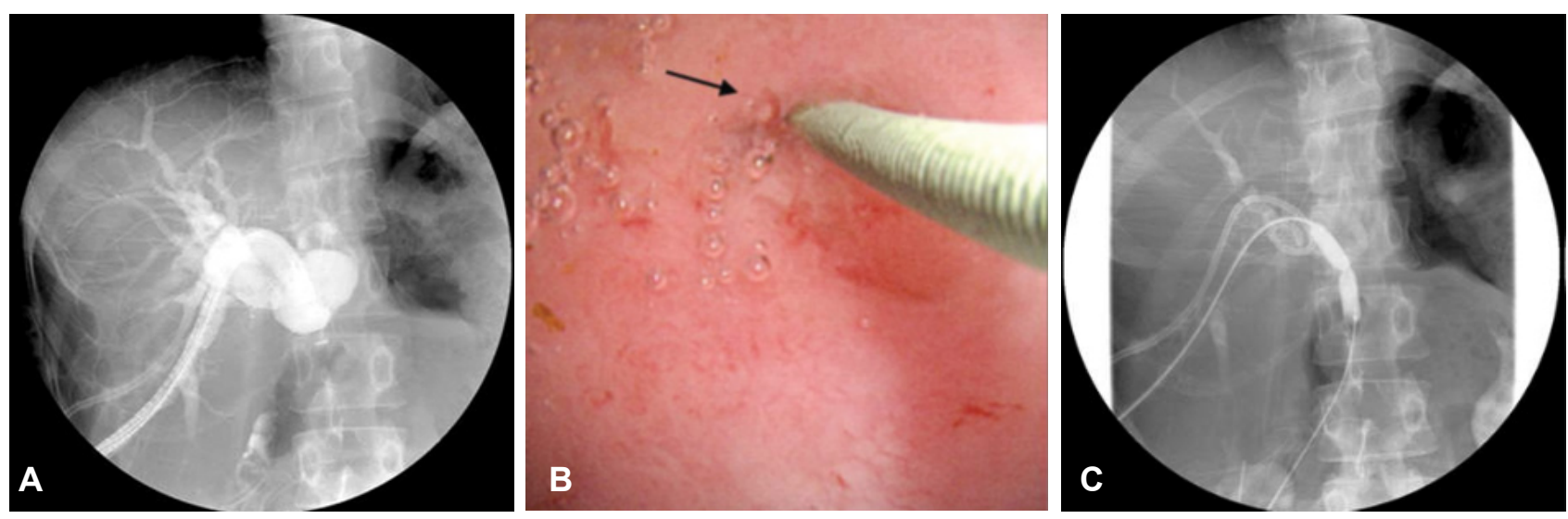

Fig. 2. (A) Cholangiography images show a bilioenteric anastomosis stricture and a marked proximal dilatation of the bile duct. (B) A pinpoint stricture (arrow) was recanalized by guide wire manipulation. (C) Balloon dilation was performed. Adapted from Yang et al. ${ }^{15}$ 
There were no significant correlations between recurrence rate and the duration of catheter maintenance or number of sessions required. ${ }^{17}$

One drawback of PTCS is that the working channel has a small diameter, and as such, a self-expandable metal stent cannot be placed through it. One study compared the temporary percutaneous placement of retrievable fully-covered metal stents with percutaneous balloon dilation in patients with benign biliary strictures. It found that the patency rates were significantly better in the metal stent group than in the balloon dilation group at 3 years ( $87 \%$ vs. $44 \%, p=0.022$ ). The indwelling period of the PTBD catheter after the initial procedure was also shorter in the metal stent group (2.5 months vs. 4.5 months, $p=0.001){ }^{18}$

PTCS is also useful in managing intractable bilioenteric strictures after balloon dilation. Although the evidence is limited to case reports, steroids (triamcinolone) can be injected directly into strictures refractory to treatment with balloon dilation and indwelling catheters. ${ }^{19}$ For cases in which conventional methods for recanalization and/or dilation fail, PTCS can be used to guide the correct placement of magnets into the stricture site. Magnetic compression anastomosis was reported to be successful in 15 of 19 patients who had treatment-refractory benign biliary strictures or duct-to-duct anastomosis strictures after liver transplantation. Recanalization was achieved and maintained in all 15 patients at 1 year postprocedure. $^{20,21}$

\section{CONCLUSIONS}

Despite the laborious preparations required, PTCS has an important role to play in the management of bilioenteric anastomosis strictures.

\section{Conflicts of Interest}

The author has no financial conflicts of interest.

\section{REFERENCES}

1. Warren KW, Mountain JC, Midell AI. Management of strictures of the biliary tract. Surg Clin North Am 1971;51:711-731.

2. Pitt HA, Miyamoto T, Parapatis SK, Tompkins RK, Longmire WP Jr. Factors influencing outcome in patients with postoperative biliary strictures. Am J Surg 1982;144:14-21.
3. Collins PG, Gorey TF. Iatrogenic biliary stricture: presentation and management. Br J Surg 1984;71:980-982.

4. Pellegrini CA, Thomas MJ, Way LW. Recurrent biliary stricture. Patterns of recurrence and outcome of surgical therapy. Am J Surg 1984;147:175180.

5. Pitt HA, Kaufman SL, Coleman J, White RI, Cameron JL. Benign postoperative biliary strictures. Operate or dilate? Ann Surg 1989;210:417425.

6. Röthlin MA, Löpfe M, Schlumpf R, Largiadèr F. Long-term results of hepaticojejunostomy for benign lesions of the bile ducts. Am J Surg 1998; $175: 22-26$

7. Tocchi A, Costa G, Lepre L, Liotta G, Mazzoni G, Sita A. The long-term outcome of hepaticojejunostomy in the treatment of benign bile duct strictures. Ann Surg 1996;224:162-167.

8. Seo DW, Lee SK, Kim MH, et al. Cholangioscopy. Seoul: Koonja Publishing Inc.; 2002.

9. Oh HC, Lee SK, Lee TY, et al. Analysis of percutaneous transhepatic cholangioscopy-related complications and the risk factors for those complications. Endoscopy 2007;39:731-736.

10. Choi JH, Lee SK. Percutaneous transhepatic cholangioscopy: does its role still exist? Clin Endosc 2013;46:529-536.

11. Seo DW, Lee SK, Yoo KS, et al. Cholangioscopic findings in bile duct tumors. Gastrointest Endosc 2000;52:630-634.

12. Kim HJ, Kim MH, Lee SK, Yoo KS, Seo DW, Min YI. Tumor vessel: a valuable cholangioscopic clue of malignant biliary stricture. Gastrointest Endosc 2000;52:635-638.

13. Bak B, Ornsholt J. Non-absorbable suture material as a nidus for the formation of common bile duct stones. Ann Chir Gynaecol 1985;74:146147.

14. Martinez J, Combs W, Brady PG. Surgical clips as a nidus for biliary stone formation: diagnosis and therapy. Am J Gastroenterol 1995;90:15211524

15. Yang DH, Lee SK, Moon SH, et al. Percutaneous transhepatic cholangioscopic intervention in the management of complete membranous occlusion of bilioenteric anastomosis: report of two cases. Gut Liver 2009;3:352-355.

16. Lim JU, Joo KR, Cha JM, et al. Needle-knife fistulotomy with percutaneous transhepatic cholangioscopy for managing complete bilioenteric anastomosis occlusion. Surg Laparosc Endosc Percutan Tech 2014;24:e10-e12.

17. Kim JH, Lee SK, Kim MH, et al. Percutaneous transhepatic cholangioscopic treatment of patients with benign bilio-enteric anastomotic strictures. Gastrointest Endosc 2003;58:733-738.

18. Kim JH, Gwon DI, Ko GY, et al. Temporary placement of retrievable fully covered metallic stents versus percutaneous balloon dilation in the treatment of benign biliary strictures. J Vasc Interv Radiol 2011;22:893899.

19. Franzini T, Moura R, Rodela G, et al. A novel approach in benign biliary stricture: balloon dilation combined with cholangioscopy-guided steroid injection. Endoscopy 2015;47 Suppl 1:E571-E572.

20. Jang SI, Kim JH, Won JY, et al. Magnetic compression anastomosis is useful in biliary anastomotic strictures after living donor liver transplantation. Gastrointest Endosc 2011;74:1040-1048

21. Jang SI, Rhee K, Kim H, et al. Recanalization of refractory benign biliary stricture using magnetic compression anastomosis. Endoscopy 2014;46:7074 